\section{P3.376 MULTIDISCIPLINARY APPROACH TO CONTAIN HIV-1 AND OTHER STIS IN CHINA: MULTIPURPOSE PREVENTION TECHNOLOGIES}

doi:10.1136/sextrans-2013-051184.0829

Z W Wu, ${ }^{2} \mathrm{~B}$ Young Holt, ${ }^{3} \mathrm{~J}$ Manning, ${ }^{4} \mathrm{~J}$ Romano, ${ }^{5} \mathrm{M}$ Lusti-Narasimhan, ${ }^{6} \mathrm{~A}$ Stone, ${ }^{7} \mathrm{C}$ Deal, ${ }^{8} \mathrm{~B}$ Wang. ${ }^{1}$ Nanjing University, Nanjing, China; ${ }^{2} \mathrm{CAMI} / \mathrm{IMPT}$, Folsom, CA, United States; ${ }^{3} U S A I D$, Washington, DC, United States; "NWJ Group, Wayne, PA, United States; ${ }^{5}$ WHO, Geneva, Switzerland; ${ }^{6}$ MEDSA LTD, London, UK; ${ }^{7}$ NIH/DMID, Washington, DC, United States: ${ }^{8}$ Chinese Academy of Medical Sciences, Nanjing, China

Background In China, the HIV prevalence continues to rise despite increasing efforts to contain the epidemic, and other sexually transmitted infections (STIs) are also on the increase. Furthermore, antibiotic-resistant STI pathogens are on the increase and many STIs facilitate the acquisition and/or transmission of HIV-1. Multipurpose prevention technologies (MPTs), including drugs, devices and vaccines that simultaneously prevent unintended pregnancies, HIV and other STIs, would provide effective approaches to meet these public health challenges.

Methods The Initiative for MPTs developed Target Product Profiles (TPPs) to define key product attributes appropriate for those regions of the world hardest hit by unintended pregnancy, HIV, and other STIs. The TPP considered priority combinations of indications, mechanisms of action, dosing and administration, and formulation and delivery. Current and historic data from China were reviewed to determine which product attributes in an MPT would best meet the needs in China.

Results Sexual transmission of HIV-1 has become the major route for new infection in China, and other STIs have increased more than 40 times from 1985. The increase in STI rates is associated with population mobility, and the geographic distribution of STIs overlaps with that of HIV, suggesting the possibility of co-infection. The rate of unintended pregnancy is low in China, given the "one child" policy. After analysing the current and historic data, we propose that MPTs specifically addressing HIV and STIs would best meet the public health challenges in China, and the preferred dosing form would be long-acting implant or IUD-based delivery.

Conclusion The continuing rise in prevalence and rates of STIs, including HIV poses serious public health challenges to China, where sustained economic development has resulted in social transformation and unprecedented population mobility. MPTs that specifically target HIV and other STIs could provide an effective approach to meeting these public health challenges in China.

\section{P3.377 "MACH'S MIT - WISSEN UND KONDOM" (“JOIN IN - KNOWLEDGE AND CONDOM") - THE COMMUNICATION STRATEGY OF THE BZGA'S INTEGRATED HIV AND STI PREVENTION CAMPAIGN}

doi:10.1136/sextrans-2013-051184.0830

V Lulei. Bundeszentrale für gesundheitliche Aufklärung (BZgA), Cologne, Germany

Background The Federal Centre for Health Education (BZgA), acting on behalf of the Federal Ministry of Health (BMG), has been implementing the central campaign GIB AIDS KEINE CHANCE (DON'T GIVE AIDS A CHANCE) in Germany since 1987. In recent years the number of STI cases has increased. The BZgA reacted to that by reorienting the central GIB AIDS KEINE CHANCE campaign and turning it into an integrated HIV/STI prevention campaign. In 2012 the protection campaign "mach's mit - Wissen und Kondom", was launched as the first integrated HIV/STI campaign in Germany. Problem description At the time of this reorientation the campaign faced the challenge of communicating basic knowledge about STIs to the German public, while at the same time maintaining the high level of information relating to HIV. Neither people's motivation to protect themselves by using condoms, nor the strong brands "GIB AIDS KEINE CHANCE" and "mach's mit", were to be weakened in the process.

Method and Conclusion The concept of the "mach's mit - Wissen und Kondom" campaign meets these challenges by dividing the communication strategy into two phases. The prevention message of the first phase builds on the HIV message "condoms protect" and introduces the concept of STIs. Since the offline media are linked to the campaign website via $\mathrm{OR}$ codes, the public can directly access basic information on HIV and other STIs. In the second, more detailed phase starting in 2014, the mass media will for the first time be used to communicate not only HIV messages, but also messages relating to protection against STIs.

Like its predecessors, the HIV/STI campaign is designed on a cross-media basis, using billboards, City-Lights, advertisements and ambient media. Accompanying activities in social media supplement the media mix.

\section{P3.378 STI TESTING IN NULLIPAROUS WOMEN DURING INTRAUTERINE DEVICE OR SYSTEM INITIATION IN CASH CLINICS (RETROSPECTIVE AUDIT)}

doi:10.1136/sextrans-2013-051184.0831

E Valarche, R Browne. St Ann's Hospital, CASH service, London, UK

Background Nulliparous women are not always offered intrauterine (IU) method of contraception due to the traditional perception from health care providers that there will be an increased rate of complications (particularly, PID). We sought to evaluate the clinical practise and STI testing during the initiation of IU method in nulliparous women in Contraceptive and Sexual Health (CASH) clinics. Study Design Electronic patient records were analysed for nulliparous women who had an IUD/IUS inserted between April 2011 and March 2012. The clinical practise was evaluated against local, FSRH and BASHH standards of care.

\section{Results}

- 423 women initiated intrauterine contraception

- 107 (25\%) nulliparous.

- Majority $(60 \%)$ were white UK ethnicity;

- Median aged 27 (range 15-49) years

- $32 \%$ aged $<25$ years

- $24 \%$ had previous TOPs

- $21 \%$ done by clinical nurse specialist

- $73 \%$ Nova T380 inserted, 4\%-Mirena IUS

- Only 7 patients had minimal side effects after procedure (abdominal discomfort)

- No uterine perforations occurred

- Follow up data available for $50 \%$ of patients

- Only 9 removals were recorded during study

- STI testing (Chlamydia and gonorrhoea, NAAT) done for 75 (70\%) patients, and 2 Chlamydia positive patients were identified (treated within 2 weeks of diagnosis, both were asymptomatic).

Conclusion Our study demonstrated a successful practise of the use of the intrauterine contraception method in nulliparous women in an integrated CASH service. The prevalence of STI was $2.5 \%$ and screening prior or at the time of IU procedure should be one of many methods of prevention of STIs and health promotion in young population and also way of "pick up" of asymptomatic STIs. Our data did not show increased risk of pelvic infection in nulliparous women with initiation of IU contraception which prove to be safe and effective method of preventing of unplanned pregnancies.

P3.379 COMPARISON IN 2004 AND 2011 ON THE EFFICACY OF PARTNER NOTIFICATION FOR CHLAMYDIA TRACHOMATIS AMONG YOUNG ADULTS IN YOUTH HEALTH CENTRES IN UPPSALA COUNTY, SWEDEN

doi:10.1136/sextrans-2013-051184.0832 